\title{
Morphological and Functional Alterations in the Aorta of the Chronically Hypoxic Fetal Rat
}

\author{
Emilio A. Herrera Emily J. Camm Christine M. Cross Joanne L. Mullender \\ F.B. Peter Wooding Dino A. Giussani \\ Department of Physiology, Development and Neuroscience, University of Cambridge, Cambridge, UK
}

\section{Key Words}

Hypoxia - Aortic function - Aortic media thickness ·

Vascular reactivity $\cdot$ Vascular remodeling

\begin{abstract}
In human pregnancy, reduced placental perfusion has been associated with fetal aortic thickening. However, the relative contributions of fetal undernutrition versus fetal underoxygenation to triggering alterations in fetal cardiovascular development remain uncertain. Here, we isolate the effects of chronic fetal hypoxia on fetal cardiovascular development in a specific rodent model of chronic fetal hypoxia independent of changes in nutrition during pregnancy. Pregnant rats were housed under normoxic $\left(21 \% \mathrm{O}_{2}\right)$ or hypoxic $\left(13 \% \mathrm{O}_{2}\right)$ conditions from day 6 to day 20 of gestation. At day 20, pups and placentas were weighed. Fetal thoraces were fixed for quantitative histological analysis of the aorta. In a separate group, fetal aortic reactivity was assessed via in vitro wire myography. The experiments controlled for sex and withinlitter variation. Placental weight was increased and fetal weight maintained in hypoxic pregnancy. Hypoxic pregnancy led to a $176 \%$ increment in wall thickness and a $170 \%$ increment in the wall-to-lumen area ratio of the fetal aorta. Fetal aortic vascular reactivity was markedly impaired, show-
\end{abstract}

ing reduced constrictor and relaxant responsiveness in hypoxic pregnancy. Chronic developmental hypoxia independent of changes in nutrition has profound effects on the morphology and function of the fetal aorta in a mammalian species.

Copyright $\odot 2011$ S. Karger AG, Basel

\section{Introduction}

Complications during pregnancy are the most important concern in obstetric medicine, being a major cause of both pre- and postnatal morbidity and mortality in the offspring $[1,2]$. Common adverse outcomes of a complicated pregnancy include a slowing of fetal growth and alterations in the development of key organs and systems, such as the heart and circulation. For instance, four separate clinical studies have reported that babies born from pregnancies complicated by intrauterine growth restriction show aortic thickening [3-6]. Placental insufficiency and preeclampsia make up an important component of these complicated pregnancies where there is a decrease in placental perfusion and, thereby, a diminished delivery of nutrients and oxygen to the developing fetus $[7,8]$. The relative contributions of fetal hypoxia versus fetal

\section{KARGER}

Fax +41613061234 E-Mail karger@karger.ch www.karger.com

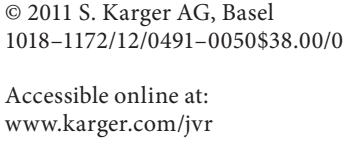

Dr. Dino A. Giussani

Department of Physiology, Development and Neuroscience

University of Cambridge

Cambridge CB2 3EG (UK)

Tel. +44 1223333 894,E-Mail dag26@ cam.ac.uk 
undernutrition in promoting adverse fetal outcomes are not fully understood. Therefore, there is increasing interest in isolating the effects of each of these challenges on fetal growth and early cardiovascular development.

More than 140 million people worldwide live $>2,500 \mathrm{~m}$ above sea level. Of them, 80 million live in Asia, and 35 million live in the Andean mountains [9]. Therefore, in humans, high-altitude pregnancy provides one of the most common forms of sustained fetal hypoxia. Studies of highland populations have reported reduced birth weight and adverse cardiovascular alterations in babies born at a high altitude relative to those born at sea level [10-17]. However, because most high-altitude populations are also impoverished, the relative contributions of hypoxia and malnutrition to fetal growth and cardiovascular development remain uncertain. Similarly, experimental isobaric hypoxia in rats has been extensively reported to promote intrauterine growth restriction and affect the postnatal development of the cardiovascular system [18-24]. Because maternal exposure to hypoxia can lead to a significant decrease in maternal food intake [25-27], the extent to which the unwanted adverse effects are due to maternal undernutrition or underoxygenation, again, remain unclear.

Several studies have employed the chick embryo as an animal model in an attempt to isolate the effects on growth and the developing cardiovascular system of chronic hypoxia, independent of changes in maternal nutrition and of the physiology of the mother and the placenta [28-34]. In mammals, only one previous study reported the relative contributions of developmental hypoxia and undernutrition to fetal alterations in somatic growth and cardiovascular structure and function in the rat [27]. However, in that study developmental hypoxia was induced in the last third of gestation, simulating lateonset complications. Further, the experimental design involved a normoxic pair-fed group to control for the hypoxia-induced reductions in maternal food intake [27]. To date, no study has investigated the effects of chronic hypoxia throughout gestation without undernutrition on fetal growth and fetal cardiovascular development in a mammalian species.

Here, we report a rat model of chronic hypoxia throughout most of gestation, simulating early-onset complications, which does not affect maternal food intake. The experimental model was used to investigate the effects of chronic hypoxia on fetal growth and on the anatomy and physiology of the fetal aorta in an attempt to isolate the relative contribution of reduced fetal oxygenation to aortic structure and reactivity.

\section{Methods}

Ethical Approval and Animal Housing

All experimental procedures were performed under the United Kingdom Animals (Scientific Procedures) Act 1986 and were approved by the Ethical Review Committee of the University of Cambridge. Wistar rats (Charles River Ltd., Margate, UK) were housed in individually ventilated cages (IVC units, $21 \% \mathrm{O}_{2}, 70-80$ air changes per hour) under standard conditions (60\% humidity, $23 \pm 1^{\circ} \mathrm{C}$, and a $12: 12$-hour light-dark cycle) with free access to food (Special Diet Services, UK) and water. After 10 days of acclimatization, virgin female Wistar rats $(n=30,10-12$ weeks of age) were paired individually with fertile male Wistar rats (minimum 12 weeks of age). The presence of a copulatory plug was considered day 0 of pregnancy (term $\sim 22$ days). Upon the confirmation of pregnancy, the female was weighed and housed individually. Maternal weight and food and water consumption were monitored daily.

\section{Experimental Design}

The pregnant rats were divided into normoxic $\left(\mathrm{N} ; 21 \% \mathrm{O}_{2}\right.$, $\mathrm{n}=15)$ or hypoxic $\left(\mathrm{H} ; 13 \% \mathrm{O}_{2}\right.$ from day 6 to day 20 of gestation, $\mathrm{n}=15$ ) pregnancies. This level of hypoxia is equivalent to $3,700-$ 4,000 m of altitude above sea level. Dams assigned to the hypoxic group were placed inside a hypoxic chamber which combined a PVC isolator (PFI Plastics Ltd., Keynes, UK) with a nitrogen generator ( $\mathrm{N}_{2} \mathrm{MID60}$; Dominick Hunter Ltd., Warwick, UK). The percentage of oxygen in the chamber was controlled by altering the inflow of air and nitrogen. The oxygen concentration was monitored continuously throughout the treatment period with an oxygen analyzer (ICA, London, UK). The chamber was housed in the same room as the normoxic IVC units. At 20 days of gestation, dams were killed by $\mathrm{CO}_{2}$ inhalation and cervical dislocation. Immediately after, all fetuses were isolated and counted and their sex was determined by measurement of the anogenital distance. In addition, maternal and fetal blood samples were taken by cardiocentesis for determination of hematocrit.

\section{Fetal Biometry and Histology}

The male fetuses and associated placentas from any one litter were weighed (body weight and placental weight, respectively) and the crown-rump length (CRL) was measured with a digital caliper. The body weight-to-placental weight ratio was calculated to asses placental efficiency. In 6 of the litters from each group, one male from any one litter was immersion fixed with $4 \%$ paraformaldehyde. Following this, the fetal trunk was embedded in paraffin and subsequently sectioned at $10 \mu \mathrm{m}$ serially starting from the area of the base of the heart until the end of the aortic arch. Six sections at the level of the end of the aortic arch from each sample were randomly selected and transferred to microscope slides. These were then stained with hematoxylin and eosin (HE) and viewed with a Leitz HM Lux microscope, and JPEG images were captured using a camera (Eurocam; Euromax, Holland) in conjunction with WinTV2000 software (Hauppage Computer Works, UK). Images were analyzed using a pixelbased Visual Basic program that extracted regional data based on the contrast between areas of a gray scale image. The program permitted calculation of the circumference of the vessel lumen (the endothelium length) and of the circumference of the vessel outer wall (the external elastic lamina length). To assess the 
thickness of the tunica media, a different set of slides was stained with antibodies against smooth muscle actin. In brief, slides were immersed in a PBS solution with $1 \%$ serum albumin and $0.5 \%$ thimerosal (DBSBT; Sigma, UK) for $5 \mathrm{~min}$. The DBSBT was removed and $50 \mu \mathrm{l}$ polyclonal immunoglobulin $\mathrm{G}$ (IgG) antimouse antibodies to smooth muscle actin (SMAD antibodies; Dako Ltd., Ely, UK) in a dilution of 1:500 was added to the slides prior to overnight incubation in a refrigerator. The next day the antibody was rinsed off thoroughly with PBS, and $50 \mu \mathrm{l}$ of monoclonal rabbit anti-mouse IgG (Dako) diluted 1:1,000 was added for $30 \mathrm{~min}$ at room temperature. After rinsing thoroughly with PBS, $50 \mu$ l of goat anti-rabbit IgG with gold particles bound (Jackson Research, Stratech Ltd., Milton Keynes, UK) was added for $40 \mathrm{~min}$ at room temperature. This was rinsed with PBS and distilled water and an enhancer (Amersham, UK) was added and left to develop for $20 \mathrm{~min}$. Images were captured in the same way as the HE sections.

\section{Wire Myography}

To asses aortic function one male per litter from the remaining 9 litters from each group was randomly selected and the fetal aorta was isolated. The thoracic aorta was placed in a petri dish in PBS kept on ice and carefully cleaned of adipose and connective tissue. An arterial segment of approximately $2 \mathrm{~mm}$ in length was cut and it was carefully threaded with a stainless steel wire $(40 \mu \mathrm{m}$ diameter). The arterial segment was then mounted on a wire myograph (Multi Wire Myograph System 610M; DMT, Denmark), it was bathed in Krebs solution (mM: $\mathrm{NaCl} 118.5, \mathrm{KCl} 4.75, \mathrm{MgSO}_{4}$. $7 \mathrm{H}_{2} \mathrm{O}$ 1.2, $\mathrm{KH}_{2} \mathrm{PO}_{4}$ 1.2, $\mathrm{NaHCO}_{3} 25.0, \mathrm{CaCl}_{2} 2.5$, and glucose 5.5; Sigma), and it was exposed continuously to a gas mixture of $5 \%$ $\mathrm{CO}_{2}$ and $95 \% \mathrm{O}_{2}$ at $37^{\circ} \mathrm{C}$ in the myograph chamber.

Following a $15-\mathrm{min}$ equilibration period, the vessel was stretched in a stepwise manner to a standardized tension equivalent to a $15-\mathrm{mm} \mathrm{Hg}$ physiologic transmural pressure. This was done to simulate conditions in vivo for two main reasons: first, because the stimulated vascular response is dependent on the degree of stretch, and second, because this degree of stretch gives the maximal vascular response [35-37]. To test the maximal contractile capacity, a potassium $\left(\mathrm{K}^{+}\right)$concentration-response curve was generated following a 20 -min equilibration period by subjecting vessel segments to increasing doses of a $\mathrm{K}^{+}$solution (4.72-125 $\mathrm{mM}$ ). Cumulative concentration-response curves to the $\alpha_{1}$-adrenergic agonist phenylephrine $\left(\mathrm{PE} ; 10^{-10}-10^{-4} \mathrm{M}\right)$ were determined in half-log increments. The endothelium-independent vasodilator effects of sodium nitroprusside (SNP; $\left.10^{-10}-10^{-4} \mathrm{M}\right)$ and the endothelium-dependent vasodilator effects of methacholine (MetCh; $10^{-10}-10^{-4} \mathrm{M}$ ) were determined after preconstriction with $\mathrm{K}^{+}(76.88 \mathrm{mM})$. To determine the contribution of endogenous nitric oxide (NO) under basal conditions, concentration-response curves were also generated for the NO synthase inhibitor L-nitroarginine methyl ester (L-NAME; $10^{-10}-10^{-3} \mathrm{M}$ ). The order of using the different agonists was randomized with the exception of LNAME treatment, which was always the last experiment. Between experiments, vessels were washed repeatedly with Krebs solution and allowed to equilibrate for at least $20 \mathrm{~min}$. At the end of all experiments, the contractile capacity to potassium was retested.

Data and Statistical Analyses

The lumen diameter (LD), vessel diameter (VD), wall thickness (WT), lumen area (LA), wall area (WA), wall thickness-to- lumen diameter ratio (WT:LD), and wall-to-lumen area ratio (WA:LA) were calculated using the following formulas:

$$
\begin{aligned}
& \mathrm{LD}=\frac{\mathrm{EL}}{\pi}, \mathrm{VD}=\frac{\mathrm{EELL}}{\pi}, \mathrm{LA}=\frac{\mathrm{LD}^{2}}{2} \times \pi, \mathrm{WT}=\frac{\mathrm{VD}-\mathrm{LD}}{2}, \\
& \mathrm{WA}=\frac{\mathrm{VD}^{2}}{2} \times \pi-\mathrm{LA} \\
& \mathrm{WT}: \mathrm{LD}=\frac{\mathrm{WT}}{\mathrm{LD}}, \mathrm{WA}: \mathrm{LA}=\frac{\mathrm{WA}}{\mathrm{LA}}
\end{aligned}
$$

The vascular responses in the myography experiments were analyzed using Prism (v.5.0; GraphPad Software) as previously described [37]. The response to potassium was analyzed using the Boltzmann sigmoidal analysis, and the maximal effective tension $\left(\mathrm{E}_{\max }\right)$ and the half maximal effective concentration $\left(\mathrm{EC}_{50}\right)$ were determined. All other concentration-response curves were analyzed using an agonist-response best-fit line, where the maximal vasomotor response was expressed as a percentage of the contraction induced by $76.88 \mathrm{mM} \mathrm{K}^{+}$(\% $\mathrm{K}_{\max }$ for constriction, $\% \mathrm{R}_{\max }$ for relaxation) and the vascular sensitivity was expressed as $\mathrm{pD}_{2}(-\log$ $\mathrm{EC}_{50}$ ).

All values reflecting ratios or percentages were arcsine transformed prior to statistical analysis. To control for sex differences and within-litter variation, data from one male pup per litter per outcome variable were taken, with the exception of any biometric variables. Biometry data were analyzed via a mixed linear model analysis of variance (ANOVA) using SPSS software (SPSS, Inc. Chicago, Ill., USA). Histology and vascular responses were compared statistically by one-way ANOVA and the Tukey post hoc test. Data are expressed as means \pm standard error of the mean (SEM). For all of the comparisons, $\mathrm{p}<0.05$ was considered statistically significant.

\section{Results}

In normoxic or hypoxic pregnancies, the maternal food intake between days 0 and 20 of gestation did not vary significantly and averaged $24.4 \pm 0.6$ and $23.9 \pm$ 0.7 g per day, respectively (fig. 1a). This daily average food intake equated to an average daily caloric intake of 299 $\pm 7 \mathrm{~kJ}$ for normoxic and $293 \pm 9 \mathrm{~kJ}$ for hypoxic pregnancies. Maternal water intake and weight gain were also similar between normoxic and hypoxic pregnancies throughout gestation (fig. $1 \mathrm{~b}, \mathrm{c}$ ). Both the maternal $(\mathrm{N}$ : $30.6 \pm 0.8 \%, \mathrm{H}: 35.5 \pm 0.6 \% ; \mathrm{p}<0.05)$ and fetal $(\mathrm{N}: 34.3$ $\pm 0.4 \%, \mathrm{H}: 41.1 \pm 0.9 \% ; \mathrm{p}<0.05)$ hematocrits were significantly increased in hypoxic relative to normoxic pregnancies.

\section{Fetal and Placental Biometry}

There was no effect of hypoxia on litter size (N: 13.4 $\pm 0.6, \mathrm{H}: 12.8 \pm 1.1 ; \mathrm{p}>0.05$, or on the number per litter of males $(\mathrm{N}: 8 \pm 1, \mathrm{H}: 6 \pm 1 ; \mathrm{p}>0.05)$ or females $(\mathrm{N}: 5$ $\pm 1, \mathrm{H}: 6 \pm 1 ; \mathrm{p}>0.05)$. Placental weight and fetal body 
Table 1. Fetal body weight and biometry

\begin{tabular}{lcc}
\hline & Normoxia & Hypoxia \\
\hline Fetal BW, g & $3.55 \pm 0.08$ & $3.66 \pm 0.05$ \\
CRL, mm & $34.96 \pm 0.39$ & $35.48 \pm 0.23$ \\
BMI & $2.879 \pm 0.060$ & $2.891 \pm 0.051$ \\
PI & $8.1654 \times 10^{-5} \pm$ & $8.13861 \times 10^{-5} \pm$ \\
& $2.53 \times 10^{-6}$ & $1.93 \times 10^{-6}$ \\
Placenta, g & $0.658 \pm 0.022$ & $0.683 \pm 0.035^{*}$ \\
BW/PW & $5.482 \pm 0.259$ & $5.542 \pm 0.254$ \\
\hline Heart & & \\
Absolute, g & $0.0257 \pm 0.0013$ & $0.0260 \pm 0.0010$ \\
Relative, \% & $0.7144 \pm 0.0259$ & $0.7070 \pm 0.0216$ \\
\hline Brain & & \\
Absolute, g & $0.1744 \pm 0.0040$ & $0.1688 \pm 0.0022$ \\
Relative, \% & $4.870 \pm 0.073$ & $4.626 \pm 0.120^{*}$ \\
\hline Liver & & \\
Absolute, g & $0.3046 \pm 0.0091$ & $0.2911 \pm 0.0072$ \\
Relative, \% & $8.511 \pm 0.230$ & $7.960 \pm 0.217$ \\
\hline Brain/liver & $0.5750 \pm 0.0136$ & $0.5855 \pm 0.0175$ \\
\hline
\end{tabular}

Values are means \pm SEM for fetal body weight, CRL, BMI, PI, placental weight, and absolute and relative-to-body-weight weights of the heart, brain, and liver at F20 for normoxic and hypoxic fetuses. ${ }^{*} \mathrm{p}<0.05$ vs. normoxia (mixed linear model). $\mathrm{BW}=$ Body weight; $\mathrm{PW}=$ placental weight.

weight and length (CRL) were appropriate for age in normoxic pregnancies at day 20 of gestation [27, 38]. Fetal body weight, CRL, the body mass index (BMI), and the ponderal index (PI) were similar in normoxic and hypoxic pregnancies (table 1). However, placental weight was significantly greater in hypoxic relative to normoxic pregnancies at day 20 of gestation. Despite this, the fetal:placental weight ratio did not differ significantly between the normoxic and hypoxic groups (table 1). In addition, heart and liver weights (absolute and relative to body weight) did not differ between groups. In contrast, hypoxic fetuses had a similar absolute brain weight but a decreased relative brain weight when compared to fetuses of normoxic pregnancies (table 1).

\section{Aortic Morphology}

The thickness and area of the aortic wall were significantly greater in fetuses from hypoxic relative to normoxic pregnancies $(\mathrm{N}: 53.3 \pm 3.8$ vs. $\mathrm{H}: 93.9 \pm 9.8 \mu \mathrm{m}$ and $\mathrm{N}: 0.081 \pm 0.007$ vs. $\mathrm{H}: 0.158 \pm 0.020 \mathrm{~mm}^{2}$, respectively; fig. 2a). However, hypoxic pregnancy did not affect the
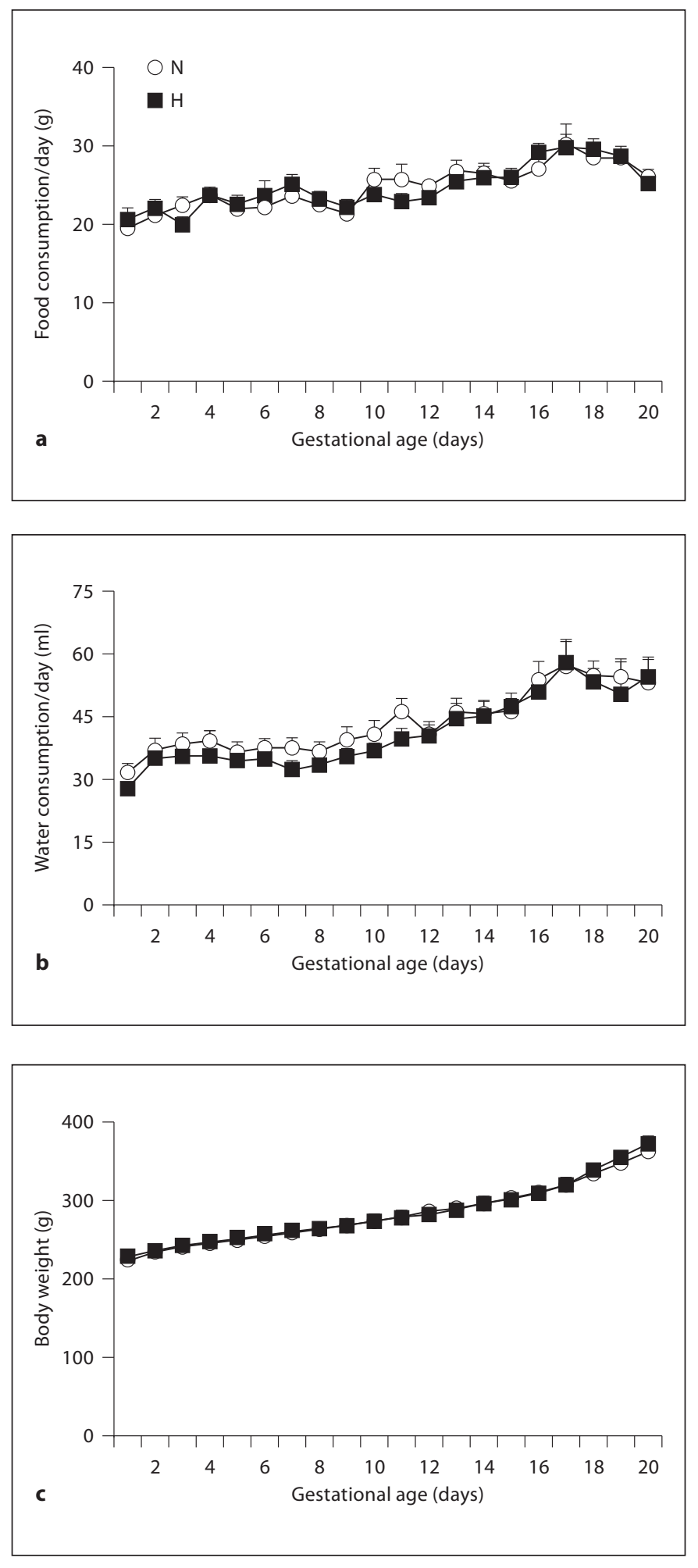

Fig. 1. Maternal food and water consumption and body weight during gestation. Values are means \pm SEM for each day of gestation for food intake (a), water intake (b), and body weight (c). Groups are normoxic $(\mathrm{N}$, open circles, $\mathrm{n}=16)$ and hypoxic $(\mathrm{H}$, solid squares, $\mathrm{n}=16$ ). 


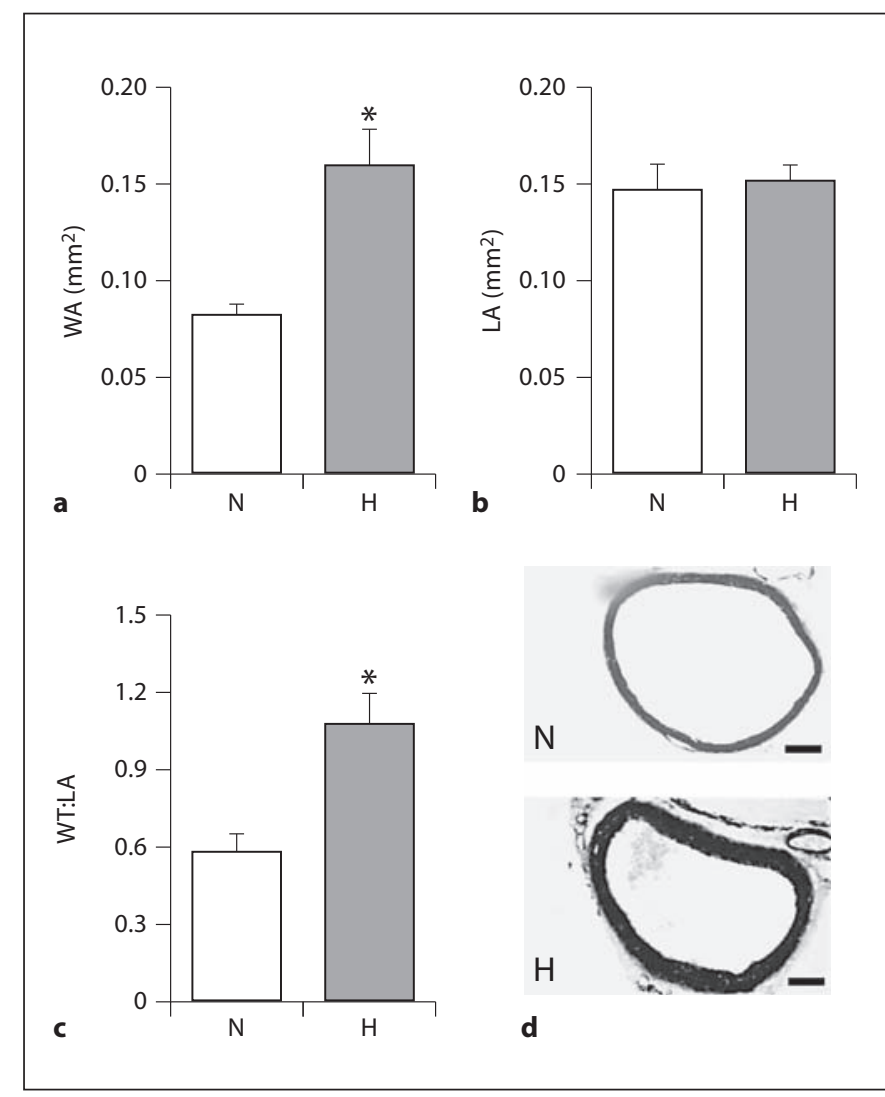

Fig. 2. Aortic wall thickening in fetal rats. Aortic remodeling in fetal rats at day 20 of pregnancy under normoxic or hypoxic conditions. Mean \pm SEM for the wall area (WA) (a), lumen area (LA) (b), and wall-to-lumen ratio (WA:LA) (c). d Representative micrographs of aortas. Scale bar $=100 \mu \mathrm{m}$. Groups are normoxic $(\mathrm{N}$, $\mathrm{n}=6)$ and hypoxic $(\mathrm{H}, \mathrm{n}=6)$. Significant differences $(\mathrm{p}<0.05)$ are: * vs. normoxia (one-way ANOVA + Tukey).

diameter and area of the fetal aortic lumen $(\mathrm{N}: 426 \pm 23$ vs. $\mathrm{H}: 435 \pm 15 \mu \mathrm{m}$ and $\mathrm{N}: 0.145 \pm 0.015$ vs. $\mathrm{H}: 0.149 \pm$ $0.009 \mathrm{~mm}^{2}$, respectively; fig. $2 \mathrm{~b}$ ). Consequently, the aortic wall-to-lumen area ratio was also significantly enhanced in fetuses from hypoxic pregnancies relative to those from normoxic pregnancies (fig. 2c). Analysis of aortic sections stained with SMAD confirmed that the thickness of the tunica media was greater in fetuses from hypoxic pregnancies compared with those from normoxic pregnancies (N: $52.9 \pm 2.1$ vs. $\mathrm{H}: 94.3 \pm 6.2 \mu \mathrm{m}$; $\mathrm{p}<$ 0.05).

\section{Aortic Vasoactive Function}

The length of the aortic segment being tested was similar for fetuses from normoxic $(1.82 \pm 0.04 \mathrm{~mm})$ or hypoxic $(1.89 \pm 0.03 \mathrm{~mm})$ pregnancies. The maximal con-
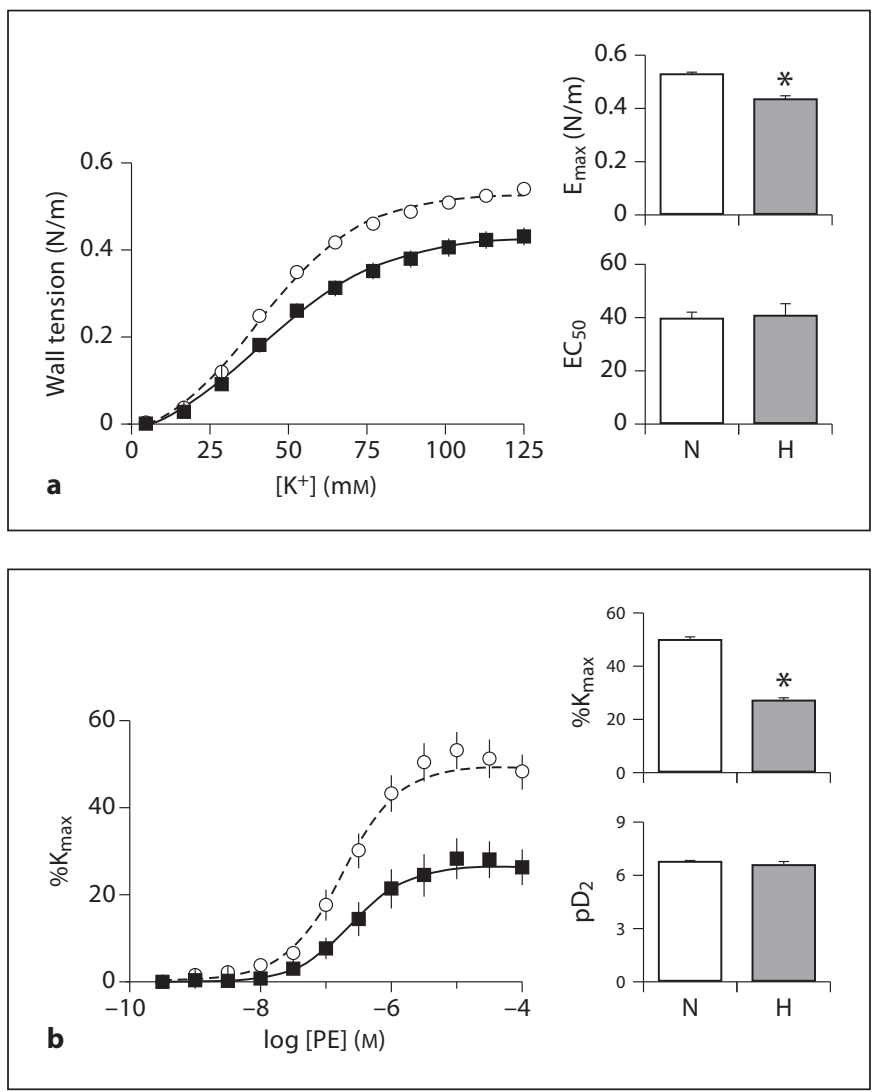

Fig. 3. Aortic vasoconstrictor function in fetal rats. Values are means \pm SEM for the concentration-response curves, the maximal constriction $\left(\mathrm{E}_{\max }\right.$ or $\left.\% \mathrm{~K}_{\max }\right)$, and the sensitivity $\left(\mathrm{EC}_{50}\right.$ or $\left.\mathrm{pD}_{2}\right)$ to potassium $\left(\mathrm{K}^{+}\right)(\mathbf{a})$ and to $\mathrm{PE}(\mathbf{b})$. Groups are normoxic $(\mathrm{N}$, open circles, $n=9)$ and hypoxic $(H$, solid squares, $n=9)$. Significant differences $(\mathrm{p}<0.05)$ are: * vs. normoxia (one-way ANOVA + Tukey).

tractile responses to $\mathrm{K}^{+}\left(\mathrm{E}_{\max }\right)$ and to $\mathrm{PE}\left(\% \mathrm{~K}_{\max }\right)$ were significantly diminished, without an effect on vascular sensitivity $\left(\mathrm{EC}_{50}\right.$ or $\left.\mathrm{pD}_{2}\right)$ to either agonist, in fetal aortas from hypoxic pregnancies compared to normoxic pregnancies (fig. 3a, b). Endothelium-independent and endothelium-dependent relaxation was assessed by generating cumulative concentration-response curves to SNP and to MetCh, respectively, following stable preconstriction with $78.66 \mathrm{mM} \mathrm{K}^{+}$. Only the maximal relaxant response and sensitivity to SNP, but not to MetCh, was significantly diminished in fetal aortas from hypoxic relative to normoxic pregnancies (fig. 4a, b). Fetal aortas from hypoxic pregnancies also showed a greatly enhanced vascular contractile response and vascular sensitivity to cumulative concentrations of L-NAME (fig. 4c). 


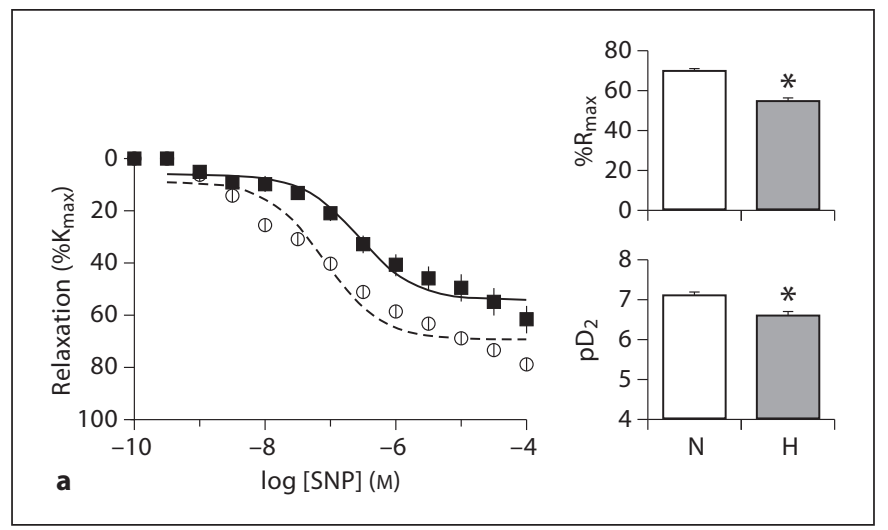

Fig. 4. Aortic vasodilator function in fetal rats. Values are means \pm SEM for the concentration-response curves, the maximal relaxation $\left(\% \mathrm{R}_{\max }\right)$, and the sensitivity $\left(\mathrm{pD}_{2}\right)$ to $\mathrm{SNP}(\mathbf{a})$, to MetCh (b), and to the NO synthase blockade L-NAME (c). Groups are normoxic (N, open circles, $n=9)$ and hypoxic $(H$, solid squares, $n=9)$. Significant differences $(p<0.05)$ are: * vs. normoxia (oneway ANOVA + Tukey).

\section{Discussion}

In rat pregnancy, uterine wall invasion and the establishment of the placenta start after day 9.25 of gestation [39]. Consequently, in this experimental model, placentation occurred during developmental hypoxia. This simulates early-onset complications during human pregnancy, such as during early-onset preeclampsia or early placental insufficiency, where there is an inadequate cytotrophoblast invasion [40-42]. This contrasts with many other studies that have investigated the effects of hypoxia during the last third of gestation in rat pregnan$\mathrm{cy}$, modeling late-onset complications in human pregnancy. In those studies, late-onset fetal hypoxia induced overt fetal asymmetric growth restriction $[21-23,27,43$, 44] without significant effects on placental weight [27, 43]. In contrast, in the present study, early-onset developmental hypoxia significantly increased placental weight without fetal growth restriction. The differences in the placental and fetal phenotypes between the studies
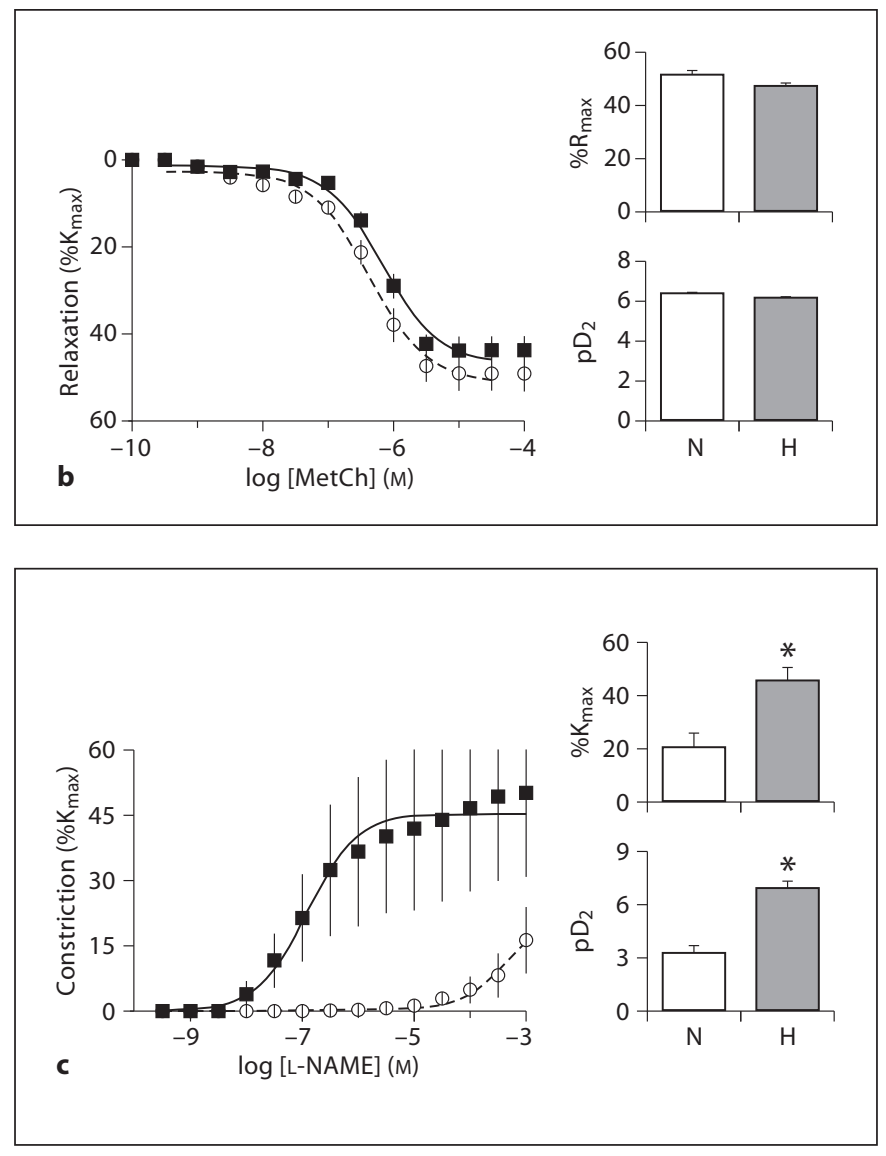

are likely due to the differential temporal growth demands of the placenta and fetus during pregnancy. In the rat, whereas placental growth starts early in gestation and continuous throughout pregnancy, fetal growth is exponential and maximal by the end of gestation [38]. Therefore, early-onset hypoxia may stimulate greaterthan-normal placental growth, cushioning the adverse effects of the challenge on fetal growth. Accordingly, studies of human pregnancy at a high altitude have reported improved placental vascularization with increased placental capillary diameter, capillary length, and capillary volume $[45,46]$.

Another interesting comparison between early-onset and late-onset chronic fetal hypoxia during development is on the morphology of the fetal aorta. Several studies have now reported in mammalian and nonmammalian species that chronic developmental hypoxia can lead to an increase in the wall-to-lumen thickness or area ratio $[27,28,33,34]$. On the basis of hemodynamics, Folkow [47] stressed a role for an increased vascular wall-to-lu- 
men ratio to be associated with an increase in resistance to flow and, thereby, an increase in perfusion pressure. In this context, fetal aortic wall thickening is particularly relevant in the clinical setting because arterial stiffness has been hailed as a key component of the etiology of hypertension, atherosclerosis, and coronary heart disease $[48,49]$. However, elegant observations by Baumbach and Heistad [50,51] and by Mulvany [52, 53] have made it clear that an increase in the ratio of the vascular wall to lumen may be achieved by at least two very different situations. For instance, the ratio may be increased by a reduction in lumenal diameter without a change in medial volume. There is thus rearrangement of the same volume of vessel wall around a smaller diameter lumen; this is now termed inward eutrophic vascular remodeling. Conversely, an increase in the vascular wall-to-lumen ratio may be achieved by an increase in wall material without a change in lumen diameter; this has been termed outward hypertrophic vascular growth. Interestingly, in the present study, early-onset chronic fetal hypoxia led to an increase in the aortic wall area without a change in the area of the lumen, characteristic of vascular outward hypertrophic growth. In support of this, the present study also reported an increase in smooth muscle actin staining in aortas of hypoxic relative to normoxic fetuses. In contrast, Camm et al. [27] reported that, in the same rat breed, late-onset chronic fetal hypoxia promoted vascular changes, more consistent with inward eutrophic remodeling of the fetal aorta. In small resistance arteries, eutrophic and hypertrophic vascular remodeling processes have been proposed to be mediated via different mechanisms [54]. Therefore, it seems probable that differential triggers also underlie fetal aortic remodeling in early- versus late-onset chronic fetal hypoxia in complicated pregnancies. In vascular hypertrophic growth, intravascular pressure causes an increase in wall stress, which then stimulates a myriad of cellular and molecular pathways including activation of stretch receptors, protooncogenes, and vascular growth trophic factors, such as VEGF and angiotensin II [33, 55-57]. In contrast, in vascular eutrophic growth, on the basis of the La Place relation, the decreased lumenal diameter will normalize vascular wall stress even on a background of increased perfusion pressure [54]. The molecular mechanisms mediating eutrophic vascular remodeling are less well understood, even for small resistance arteries. However, it has been reported that $\alpha \mathrm{V}$ integrins are necessary for the process [58]. Clearly, the aorta is not a resistance vessel; its functions are to buffer systolic blood pressure and to use this stored energy to help propel blood flow along the systemic circulation. However, the morphologic changes observed in this study, consistent with vascular outward hypertrophic growth, do suggest an enhanced cardiac afterload in this mammalian model of early-onset fetal chronic hypoxia.

Our functional studies with in vitro wire myography showed that early-onset chronic fetal hypoxia leads to a markedly reduced contractile response to potassium and PE. In contrast, late-onset chronic fetal hypoxia led to an increase in the contractile sensitivity to potassium with no change in reactivity to PE [27]. These findings highlight evidence of muscular contractile impairment in the fetal aorta, despite an enhanced medial mass, in pregnancies complicated by early-onset fetal chronic hypoxia.

In the rat, the endothelial vasodilator function in the fetal aorta is primarily determined by NO and EDHF [59]. The present study shows that, in contrast to lateonset fetal hypoxia [27], in addition to the weakened muscular vasoconstrictor function there is a reduced relaxant response to the NO donor, SNP, but a greatly enhanced constrictor response to the NO synthase blocker LNAME. Combined, these data may reflect decreased expression and/or activity of proteins that act in the NOcGMP dilator pathway, although the effective concentration of NO mitigated by superoxide might also be considered. The enhanced NO production in fetal aortas from hypoxic relative to normoxic pregnancies suggests that aortas from fetuses of hypoxic pregnancies tonically release dilator quantities of NO but that any release from aortas of fetuses from normoxic pregnancies is minimal. A greater tonic release of NO may represent a compensatory response to the reduced expression or activity of proteins involved in the NO pathway. Other examples of feedback within the NO pathway have been previously described. For instance, chronic increases in NO, due to eNOS expression, activity, or both, are accompanied by downregulation of sGC expression $[60,61]$ and increased PDE function [62]. It is possible that the enhanced NO bioavailability in fetal aortas during early-onset chronic fetal hypoxia may be partly responsible for the diminished constrictor reactivity to potassium and PE. Muscular aortic contractile and relaxant impairment, despite an enhanced medial mass, may indicate not only greater cardiac afterload but also a reduced buffering capacity against systolic blood pressure and a diminished ability to store and use this energy to help propel blood flow along the systemic circulation in male fetuses from pregnancies complicated by early-onset chronic hypoxia.

In conclusion, the data show for the first time in a mammalian species that developmental hypoxia inde- 
pendent of changes in nutrition has a significant effect on the morphology and reactivity of the male fetal aorta in the rat. Developmental hypoxia per se rather than undernutrition may thus be the mechanism via which placental insufficiency has been reported to induce aortic thickening in human infants in four separate clinical studies [36]. The data also highlight important differences in the effects of early- versus late-onset fetal chronic hypoxia during development on placental and fetal growth and on the structure and reactivity of the fetal aorta.

\section{Acknowledgments}

We are thankful to the Central Biomedical Resources (CBS), University of Cambridge, for their excellent technical assistance and help with the animal maintenance.

Emilio A. Herrera is a fellow of the Beca Presidente de la Republica (CONICYT) from the Chilean Government. Dino A. Giussani is a Royal Society Wolfson Research Merit Award holder. This work was supported by The British Heart Foundation and the BBSRC.

\section{References}

1 Caulfield LE, de Onis M, Blössner M, Black RE: Undernutrition as an underlying cause of child deaths associated with diarrhea, pneumonia, malaria, and measles. Am J Clin Nutr 2004;80:193-198.

2 Steer P: The epidemiology of preterm labour. BJOG 2005;112(suppl 1):1-3.

>3 Skilton MR, Evans N, Griffiths KA, Harmer JA, Celermajer DS: Aortic wall thickness in newborns with intrauterine growth restric tion. Lancet 2005;365:1484-1486.

$\checkmark 4$ Koklu E, Kurtoglu S, Akcakus M, Koklu S, Buyukkayhan D, Gumus H, Yikilmaz A: Increased aortic intima-media thickness is related to lipid profile in newborns with intrauterine growth restriction. Horm Res 2006; 65:269-275.

5 Akira M, Yoshiyuki S: Placental circulation, fetal growth, and stiffness of the abdominal aorta in newborn infants. J Pediatr 2006;148: 49-53.

6 Cosmi E, Visentin S, Fanelli T, Mautone AJ, Zanardo V: Aortic intima media thickness in fetuses and children with intrauterine growth restriction. Obstet Gynecol 2009; 114:1109-1114

7 Ergaz Z, Avgil M, Ornoy A: Intrauterine growth restriction-etiology and consequences: what do we know about the human situation and experimental animal models? Reprod Toxicol 2005;20:301-322.

$>8$ Cetin I, Alvino G: Intrauterine growth restriction: implications for placental metabolism and transport: a review. Placenta 2009; 30(suppl A):S77-S82.

$\checkmark 9$ Penaloza D, Arias-Stella J: The heart and pulmonary circulation at high altitudes: healthy highlanders and chronic mountain sickness. Circulation 2007;115:1132-1146.

10 Lichty JA, Ting RY, Bruns PD, Dyar E: Studies of babies born at high altitudes. 1. Relation of altitude to birth weight. AMA J Dis Child 1957;93:666-669.

-11 McCullough RE, Reeves JT: Fetal growth retardation and increased infant mortality at high altitude. Arch Environ Health 1977;32: 36-39.
12 Zamudio S, Palmer SK, Dahms TE, Berman JC, McCullough RG, McCullough RE, Moore LG: Blood volume expansion, preeclampsia, and infant birth weight at high altitude. J Appl Physiol 1993;75:1566-1573.

13 Giussani DA, Phillips PS, Anstee S, Barker DJ: Effects of altitude versus economic status on birth weight and body shape at birth. Pediatr Res 2001;49:490-494.

14 Keyes LE, Armaza JF, Niermeyer S, Vargas E, Young DA, Moore LG: Intrauterine growth restriction, preeclampsia, and intrauterine mortality at high altitude in Bolivia. Pediatr Res 2003;54:20-25.

15 Penaloza D, Arias-Stella J, Sime F, Recavarren S, Marticorena E: The heart and pulmonary circulation in children at high altitudes: physiological, anatomical, and clinical observations. Pediatrics 1964;34:568-582.

-16 Hartinger S, Tapia V, Carrillo C, Bejarano L, Gonzales GF: Birth weight at high altitudes in Peru. Int J Gynaecol Obstet 2006;93:275-281.

17 Huicho L, Niermeyer S: Cardiopulmonary pathology among children resident at high altitude in Tintaya, Peru: a cross-sectional study. High Alt Med Biol 2006;7:168-179.

18 Xiao D, Ducsay CA, Zhang L: Chronic hypoxia and developmental regulation of cytochrome c expression in rats. J Soc Gynecol Investig 2000;7:279-283.

-19 Peyronnet J, Dalmaz Y, Ehrström M, Mamet J, Roux JC, Pequignot JM, Thorén HP, Lagercrantz H: Long-lasting adverse effects of prenatal hypoxia on developing autonomic nervous system and cardiovascular parameters in rats. Pflugers Arch 2002;443:858-865.

20 Li G, Xiao Y, Estrella JL, Ducsay CA, Gilbert RD, Zhang L: Effect of fetal hypoxia on heart susceptibility to ischemia and reperfusion injury in the adult rat. J Soc Gynecol Investig 2003;10:265-274.

-21 Zaobornyj T, Valdez LB, Iglesias DE, Gasco M, Gonzales GF, Boveris A: Mitochondrial nitric oxide metabolism during rat heart adaptation to high altitude: effect of sildenafil L-NAME, and L-arginine treatments. Am J Physiol Heart Circ Physiol 2009;296:H1741H1747.
22 Williams SJ, Campbell ME, McMillen IC, Davidge ST: Differential effects of maternal hypoxia or nutrient restriction on carotid and femoral vascular function in neonatal rats. Am J Physiol Regul Integr Comp Physiol 2005;288:R360-R367.

-23 Rueda-Clausen CF, Morton JS, Davidge ST: Effects of hypoxia-induced intrauterine growth restriction on cardiopulmonary structure and function during adulthood. Cardiovasc Res 2009;81:713-722.

24 de Grauw TJ, Myers RE, Scott WJ: Fetal growth retardation in rats from different levels of hypoxia. Biol Neonate 1986;49:85-89.

25 Meberg A: Somatic growth and brain development: effects of intrauterine malnutrition and hypoxia in mice. Biol Neonate 1981;39: 272-284.

26 Schwartz JE, Kovach A, Meyer J, McConnell C, Iwamoto HS: Brief, intermittent hypoxia restricts fetal growth in Sprague-Dawley rats. Biol Neonate 1998;73:313-319.

27 Camm EJ, Hansell JA, Kane AD, Herrera EA, Lewis C, Wong S, Morrell NW, Giussani DA: Partial contributions of developmental hypoxia and undernutrition to prenatal alterations in somatic growth and cardiovascular structure and function. Am J Obstet Gynecol 2010;203:495.e24-34.

$>28$ Rouwet EV, Tintu AN, Schellings MW, van Bilsen M, Lutgens E, Hofstra L, Slaaf DW, Ramsay G, Le Noble FA: Hypoxia induces aortic hypertrophic growth, left ventricular dysfunction, and sympathetic hyperinnervation of peripheral arteries in the chick embryo. Circulation 2002;105:2791-2796.

29 Miller SL, Green LR, Peebles DM, Hanson MA, Blanco CE: Effects of chronic hypoxia and protein malnutrition on growth in the developing chick. Am J Obstet Gynecol 2002; 186:261-267.

30 Villamor E, Kessels CG, Ruijtenbeek K, van Suylen RJ, Belik J, de Mey JG, Blanco CE: Chronic in ovo hypoxia decreases pulmonary arterial contractile reactivity and induces biventricular cardiac enlargement in the chicken embryo. Am J Physiol Regul Integr Comp Physiol 2004;287:R642-R651. 
-31 Giussani DA, Salinas CE, Villena M, Blanco $\mathrm{CE}$ : The role of oxygen in prenatal growth: studies in the chick embryo. J Physiol 2007; 585:911-917.

32 Mortola JP, Cooney E: Cost of growth and maintenance in chicken embryos during normoxic or hypoxic conditions. Respir Physiol Neurobiol 2008;162:223-229.

>33 Tintu A, Rouwet E, Verlohren S, Brinkmann J, Ahmad S, Crispi F, van Bilsen M, Carmeliet P, Staff AC, Tjwa M, Cetin I, Gratacos E, Hernandez-Andrade E, Hofstra L, Jacobs M, Lamers WH, Morano I, Safak E, Ahmed A, le Noble F: Hypoxia induces dilated cardiomyopathy in the chick embryo: mechanism, intervention, and long-term consequences. PLoS One 2009; 4:e5155.

-34 Salinas CE, Blanco CE, Villena M, Camm EJ, Tuckett JD, Weerakkody RA, Kane AD, Shelley AM, Wooding FB, Quy M, Giussani DA: Developmental origin of cardiac and vascular disease in chick embryos incubated at high attitude. J Dev Orig Health Dis 2010;1: 60-66.

>35 Mulvany MJ, Halpern W: Contractile properties of small arterial resistance vessels in spontaneously hypertensive and normotensive rats. Circ Res 1977;41:19-26.

$>36$ Kusinski LC, Baker PN, Sibley CP, Wareing $\mathrm{M}$ : In vitro assessment of mouse uterine and fetoplacental vascular function. Reprod Sci 2009;16:740-748.

37 Herrera EA, Verkerk MM, Derks JB, Giussani DA: Antioxidant treatment alters peripheral vascular dysfunction induced by postnatal glucocorticoid therapy in rats. PLoS One 2010;5:e9250.

-38 Witlin AG, Li ZY, Wimalawansa SJ, Grady JJ, Grafe MR, Yallampalli C: Placental and fetal growth and development in late rat gestation is dependent on adrenomedullin. Biol Reprod 2002;67:1025-1031.

>39 Ellington SK: A morphological study of the development of the chorion of rat embryos. J Anat 1987; 150:247-263.

-40 Wang A, Rana S, Karumanchi SA: Preeclampsia: the role of angiogenic factors in its pathogenesis. Physiology (Bethesda) 2009;24:147-158.
41 Neerhof MG, Thaete LG: The fetal response to chronic placental insufficiency. Semin Perinatol 2008;32:201-205.

42 Myatt L, Webster RP: Vascular biology of preeclampsia. J Thromb Haemost 2009;7: 375-384.

43 Gilbert M, Leturque A: Fetal weight and its relationship to placental blood flow and placental weight in experimental intrauterine growth retardation in the rat. J Dev Physiol 1982;4:237-246.

44 Xu Y, Williams SJ, O’Brien D, Davidge ST: Hypoxia or nutrient restriction during pregnancy in rats leads to progressive cardiac remodeling and impairs postischemic recovery in adult male offspring. FASEB J 2006;20: 1251-1253

45 Mayhew TM: Changes in fetal capillaries during preplacental hypoxia: growth, shape remodelling and villous capillarization in placentae from high-altitude pregnancies. Placenta 2003;24:191-198.

46 Cartwright JE, Keogh RJ, Tissot van Pato MC: Hypoxia and placental remodelling. Adv Exp Med Biol 2007;618:113-126.

47 Folkow B: Physiological aspects of primary hypertension. Physiol Rev 1982;62:347-504.

48 Arnett DK, Evans GW, Riley WA: Arterial stiffness: a new cardiovascular risk factor? Am J Epidemiol 1994;140:669-682.

49 Boutouyrie P, Tropeano AI, Asmar R, Gautier I, Benetos A, Lacolley P, Laurent S: Aortic stiffness is an independent predictor of primary coronary events in hypertensive patients: a longitudinal study. Hypertension 2002;39:10-15.

50 Baumbach GL, Heistad DD: Remodeling of cerebral arterioles in chronic hypertension. Hypertension 1989;13:968-972.

51 Baumbach GL, Heistad DD: Adaptive changes in cerebral blood vessels during chronic hypertension. J Hypertens 1991;9:987-991.

52 Mulvany MJ: Vascular remodelling in hypertension. Eur Heart J 1993;14(suppl C): $2-4$.
53 Mulvany MJ: Vascular remodelling of resistance vessels: can we define this? Cardiovasc Res 1999;41:9-13.

54 Mulvany MJ: Small artery remodeling and significance in the development of hypertension. News Physiol Sci 2002;17:105-109.

55 Anderson PA, Kleinman CS, Lister G, Talner NS: Cardiovascular function during normal fetal and neonatal development and with hypoxic stress; in Polin RA, Fox WW (eds): Fetal and Neonatal Physiology. Philadelphia, Saunders, 1998.

56 Kempf H, Linares C, Corvol P, Gasc JM: Pharmacological inactivation of the endothelin type A receptor in the early chick embryo: a model of mispatterning of the branchial arch derivatives. Development 1998; 125:4931-4941.

57 Byrne AM, Bouchier-Hayes DJ, Harmey JH: Angiogenic and cell survival functions of vascular endothelial growth factor (VEGF). J Cell Mol Med 2005;9:777-794.

58 Heerkens EH, Shaw L, Ryding A, Brooker G, Mullins JJ, Austin C, Ohanian V, Heagerty AM: $\alpha \mathrm{V}$ integrins are necessary for eutrophic inward remodeling of small arteries in hypertension. Hypertension 2006;47:281287.

59 Martínez-Orgado J, González R, Alonso MJ, Marín J: Nitric oxide-dependent and -independent mechanisms in the relaxation elicited by acetylcholine in fetal rat aorta. Life Sci 1999;64:269-277.

60 Yamashita T, Kawashima S, Ohashi Y, Ozaki M, Rikitake Y: Mechanisms of reduced nitric oxide/cGMP-mediated vasorelaxation in transgenic mice overexpressing endothelial nitric oxide synthase. Hypertension 2000; 36:97-102.

61 Gunnett CA, Lund DD, Chu Y, Brooks RM 2nd, Faraci FM: NO-dependent vasorelaxation is impaired after gene transfer of inducible NO-synthase. Arterioscler Thromb Vasc Biol 2001;21:1281-1287.

-62 Rybalkin SD, Yan C, Bornfeldt KE, Beavo JA: Cyclic GMP phosphodiesterases and regulation of smooth muscle function. Circ Res 2003;93:280-291. 